ORIGINAL RESEARCH ARTICLE

\title{
A Predictive Performance of STOP-BANG Score and Epworth Sleepiness Scale in Suspected Sleep Apnea Individuals
}

\author{
Keyur M Patel ${ }^{1}$, Nalin T Shah ${ }^{2}$
}

\begin{abstract}
Background: Incidence of sleep apnea is rising globally. STOP-BANG (Snoring, Tiredness, Observed choking, Pressure, Body Mass Index (BMI), Age, Neck girth, Gender) Score and Epworth sleepiness scale (ESS) are outpatient assessment scores available to suspect and estimate the severity of obstructive sleep apnea (OSA) that is compared with gold standard test overnight polysomnography.

Objective: The objective of the article was to validate and establish a correlation of variables of STOP-BANG Score, ESS, and Apnea-Hypopnea Index (AHI) from polysomnography.

Methods: Retrospective study in patients aged 18 or more who were referred to the Department of Pulmonary Medicine, BJMC, Ahmedabad, between April 2017 and December 2020 who had complaints of excessive daytime sleepiness underwent overnight polysomnography after physical examination in the outpatient department.

Results: Of our study population ( $n=200)$, number of men were $137(68.5 \%)$ and women were $63(31.5 \%)$ with a male:female ratio of 2.17:1. Mean BMI, neck girth, ESS, STOP-BANG Score, and AHI were $32.78 \pm 6.9 \mathrm{~kg} / \mathrm{m}^{2}, 39.49 \pm 5.97 \mathrm{~cm}, 14.48 \pm 3.91,5.34 \pm 1.7$, and 48.22 \pm 23 , respectively, and the number of patients according to severity was mild 16 (8\%), moderate $36(18 \%)$, and severe $146(73 \%)$. The Pearson correlation counted between neck girth $(r=0.68)$, ESS $(r=0.73)$ and STOP-BANG Score $(r=0.55)$ with AHI with a significant $p$ value $(<0.0001)$.

Conclusion: Snoring is the most common symptom in suspected OSA individuals. The study showed a positive correlation of BMI, neck girth, ESS $>10$, STOP-BANG Score $>3$ with severity of OSA depicted in polysomnography.
\end{abstract}

Keywords: Apnea-Hypopnea Index, Epworth sleepiness scale, Obstructive sleep apnea, obese, gender and age, Snoring, STOP-BANG questionnaire.

Indian Journal of Sleep Medicine (2021): 10.5005/jp-journals-10069-0083

\section{INTRODUCTION}

Worldwide, rates of overweight and obesity have raised three times in the past 40 years. ' There are around 2 billion adults overweight, of those 650 million are considered to be affected by obesity (Body Mass Index (BMI) $\geq 30 \mathrm{~kg} / \mathrm{m}^{2}$ ). That equates to $39 \%$ (39\% of men and $40 \%$ of women) of adults aged 18 or over who were overweight, with $13 \%$ obese. The worldwide prevalence of obesity nearly tripled between 1975 and 2016. If current trends continue, it is estimated that 2.7 billion adults will be overweight, over 1 billion affected by obesity, and 177 million adults severely affected by obesity by 2025 . $^{2}$ From 1975 to 2014 , age-standardized obesity (BMI $\geq 30 \mathrm{~kg} / \mathrm{m}^{2}$ ) increased up to three times $(10.8 \%$ ) in men; and 2.5 times (14.9\%) in women. ${ }^{3}$ In 2017, 39\% of world population suffered from overweight $\left(\mathrm{BMI}>25 \mathrm{~kg} / \mathrm{m}^{2}\right)$ and $13 \%$ were obese $\left(\mathrm{BMI}>30 \mathrm{~kg} / \mathrm{m}^{2}\right) .{ }^{4}$ As per recent data of 2019-2020 of the age of 15-49 years of the Indian population, the prevalence of overweight and obesity was $18.7 \%$ ( $20 \%$ of men and $17.2 \%$ of women) and $5.5 \%$ (4.7\% of men and $6.3 \%$ of women), respectively. ${ }^{5}$

Snoring is a highly prevalent disorder, ${ }^{6,7}$ and it is one of the most common symptoms of obstructive sleep apnea syndrome (OSAS) and may affect sleep architecture and quality of sleep. Therefore, snoring must be screened and considered as an important element of OSAS. ${ }^{8,9}$ Patient himself usually does not aware of his snoring. Mostly, family members raise the problem of snoring that makes a reason for consultation. It is a typical inspiratory breathing noise occurring during sleep, even though a small expiratory component can be heard. .,10,11 $^{\text {The sound source }}$ is the segment pharyngeal upper airways. It is the audible sign of increased upper airway resistance. ${ }^{12}$
1,2Department of Pulmonary Medicine, BJ Medical College, Ahmedabad, Gujarat, India

Corresponding Author: Keyur M Patel, Department of Pulmonary Medicine, BJ Medical College, Ahmedabad, Gujarat, India, Phone: +91 8866674417, +91 8200759371, e-mail: kur.mbbs276@gmail.com

How to cite this article: Patel KM, Shah NT. A Predictive Performance of STOP-BANG Score and Epworth Sleepiness Scale in Suspected Sleep Apnea Individuals. Indian J Sleep Med 2021;16(3):69-76.

Source of support: Nil

Conflict of interest: None

Habitual snoring (HS) has also been associated with impaired glucose tolerance ${ }^{13}$ and obesity. ${ }^{14}$ Obesity and neck circumference are the risk factors for snoring; moreover, increased negative intraluminal pressure during breathing leads to collapse of upper airway and vibration of pharynx. ${ }^{15}$

In a few studies, weight problems were regarded to be causal in snoring ${ }^{16}$ however, there has been an increasing number of puzzles as similar studies confirmed that weight loss had very modest consequences on snoring. ${ }^{17,18}$ Other studies, however, indicate that HS will also be connected to weight gain via way of means of contributing to metabolic load. ${ }^{13} \mathrm{HS}$ seems to boom dangerous elements related to weight problems inclusive of sleep fragmentation, impaired circulatory function, hypertension, metabolic syndrome, diabetes, and impaired glucose control. ${ }^{13,14}$

A large neck circumference has been related to a multiplied danger of OSA. Neck circumference can also additionally correlate with OSA higher than BMI. In one study, subjects with OSA have 
a neck circumference $40 \mathrm{~cm}$ more than subjects without OSA. Neck girth $>40 \mathrm{~cm}$ had a sensitivity of $61 \%$ and specificity of $91 \%$, irrespective of the person's sex. ${ }^{19}$

The occurrence of hypertension has been anticipated $50-60 \%$ of recognized OSA and OSA has been suggested $>30 \%$ of hypertensive individual ${ }^{20}$ and can be a reason for drug-resistant hypertension. ${ }^{21}$

Although obstructive sleep apnea is a pretty regularly occurring sickness in both men and women, only a few instances are understood for intercourse variations withinside the pathogenesis of this sickness.

Initial studies ${ }^{22-24}$ indicated that sleep apnea becomes a whole lot greater in men than in women. It becomes at the start idea that the male-to-female ratio for obstructive sleep apnea becomes 8:1. However, most latest and rigorous epidemiological studies ${ }^{23,24}$ have proven that the male-to-female ratio for sleep apnea is 2:1. Youngs reported a prevalence of excessive daytime drowsiness-related OSA in a population of $30-60$ years of age to be $4 \%$ in men and $2 \%$ in women. Studies have shown that the clinical symptoms of sleep apnea are similar in men and women, but the prevalence is increasing in men. ${ }^{25}$ One of the reasons for the high prevalence in men may be that women are less likely to report symptoms associated with sleep apnea. ${ }^{26}$ However, some studies ${ }^{27-30}$ show sex differences due to differences in the structure and physiological behavior of the upper airways. These data imply not only that gender differences in the prevalence of sleep apnea are associated with underreporting of symptoms, but also that men and women are associated with pathological differences in symptoms of the condition.

\section{Methods}

\section{Subjects}

We retrospectively analyzed 200 records of patients aged 18 or more who were referred to the Department of Pulmonary Medicine, BJMC, Ahmedabad, between April 2017 and December 2020 who had complaints of excessive daytime sleepiness. We have done the physical examination, and anthropometric features like age, BMI, and neck circumference were recorded. All individuals were evaluated for Epworth sleepiness scale (ESS) and calculated STOP-BANG Score. Then in eligible patients, we performed level II polysomnography.

\section{Polysomnography}

Respiratory polygraphy done an overnight period of a minimum of 6-hour duration was performed to all participants and included the following: measurement of blood oxygen saturation by pulse oximetry and nasobuccal airflow, position analysis, and snoring quantification with recording of tracheal sound from an air-coupled microphone (sensor) attached on the neck. When the larynx vibrates sufficiently, the sensor detects the vibration and records the loud breathing time of respiratory cycle. Polygraphy recordings were scored according to the criteria of the American Academy of Sleep Medicine. ${ }^{31-33}$ Apnea is defined as complete cessation of airflow at least 10s. Hypopnea is defined as the reduction of more than $30 \%$ of the airflow signal with an associated fall of at least 3\% in oxygen saturation. Apnea-Hypopnea Index (AHI) was defined as the number of apneas and hypopneas per hour of sleep. Patients with AHI at least five events per hour were diagnosed as having OSAS. As a result of polysomnography, patients were classified into four groups according to AHI: normal (AHI <5), mild OSAS group ( $5 \leq \mathrm{AHI}<15$ ), moderate OSAS group $(15 \leq \mathrm{AHI}<30)$, and severe OSAS group $(A H I \geq 30)$. ESS divided into the following category: $0-10=$ normal range of sleepiness, $11-14=$ slight sleepiness, $15-17=$ moderate sleepiness, and 18-24 = intense sleepiness. ${ }^{34}$

\section{Statistical Analysis}

Statistical analysis was achieved with SPSS 20.0 software. All statistics were provided as a mean \pm SD for continuous variables and frequencies (percent) for categorical variables. Difference in the proportion of categorical variables was assessed by $t$-test and Chi-square test. Pearson correlation coefficient was used to research among the total AHI with neck circumference, ESS, and STOP-BANG Score by socscistatics.com facility.

\section{Results}

In our study population ( $n=200)$, a number of men were 137 (68.5\%) and women were $63(31.5 \%)$ with a male: female ratio of 2.17:1. Mean BMI, neck girth, ESS, STOP-BANG Score, and AHI were $32.78 \pm 6.9 \mathrm{~kg} / \mathrm{m}^{2}, 39.49 \pm 5.97 \mathrm{~cm}, 14.48 \pm 3.91,5.34 \pm 1.7$, and $48.22 \pm 23$, respectively. The baseline traits of 200 patients in our study are presented in Table 1.

Table 1: Baseline characteristic of 200 patients

\begin{tabular}{|c|c|}
\hline \multicolumn{2}{|l|}{ All patients data } \\
\hline Variables & $n=200$ \\
\hline Age (years) & $51.82 \pm 13.4$ \\
\hline $\operatorname{Sex}(M / F)$ & $2.17: 1$ \\
\hline Weight (kg) & $86.19 \pm 19.93$ \\
\hline Height (cm) & $161.89 \pm 10.22$ \\
\hline $\mathrm{BMI}\left(\mathrm{kg} / \mathrm{m}^{2}\right)$ & $32.78 \pm 6.90$ \\
\hline Neck girth (cm) & $39.49 \pm 5.97$ \\
\hline ESS & $14.48 \pm 3.91$ \\
\hline STOP-BANG & $5.34 \pm 1.70$ \\
\hline $\mathrm{AHI}$ & $48.22 \pm 24.53$ \\
\hline STOP-BANG & $\mathrm{n}(\%)$ \\
\hline Snoring & $179(89.5)$ \\
\hline Tiredness & $179(89.5)$ \\
\hline Observed choking & $144(72)$ \\
\hline Pressure & $136(68)$ \\
\hline $\mathrm{BMI}>35 \mathrm{~kg} / \mathrm{m}^{2}$ & $68(34)$ \\
\hline Age $>50$ years & $112(56)$ \\
\hline Neck girth $>40 \mathrm{~cm}$ & $123(61.5)$ \\
\hline Gender & $137(68.5)$ \\
\hline STOP-BANG Score & $\mathrm{n}(\%)$ \\
\hline $0-2$ & $15(7.5)$ \\
\hline $3-4$ & $40(20)$ \\
\hline$\geq 5$ & $145(72.5)$ \\
\hline Obesity & $\mathrm{n}(\%)$ \\
\hline Obese $\left(\mathrm{BMI} \geq 30 \mathrm{~kg} / \mathrm{m}^{2}\right)$ & $137(68.5)$ \\
\hline Morbid obese (BMI $\geq 40 \mathrm{~kg} / \mathrm{m}^{2}$ ) & $32(16)$ \\
\hline Severity of OSA & $\mathrm{n}(\%)$ \\
\hline Normal & $2(1)$ \\
\hline Mild & $16(8)$ \\
\hline Moderate & $36(18)$ \\
\hline Severe & $146(73)$ \\
\hline
\end{tabular}


As shown in Table 2, women with higher BMI have more risk of OSA. Other variables are evenly distributed in both the sexes.

There were $68.5 \%(n=137)$ obese and $16 \%(n=32)$ morbid obese individuals (Table 3 ). BMI $\geq 30$ increases the risk of OSA without making a significant difference in obese and morbid obese individuals.

As shown in Table 4, the higher the STOP-BANG Score, the higher the chance of getting sleep apnea. STOP-BANG Score $\geq 3$ is significantly raising suspicion of sleep disordered breathing (SDB).

Table 2: Baseline characteristics of different gender groups

\begin{tabular}{|c|c|c|c|}
\hline Gender & Men $(n=137)$ & Women $(n=63)$ & $p$ value \\
\hline Age (years) & $50.80 \pm 13.23$ & $54.03 \pm 13.61$ & 0.11 \\
\hline Weight (kg) & $86.46 \pm 20.38$ & $85.62 \pm 19.06$ & 0.78 \\
\hline Height (cm) & $164.27 \pm 9.69$ & $156.73 \pm 9.49$ & $<0.0001$ \\
\hline BMI $\left(\mathrm{kg} / \mathrm{m}^{2}\right)$ & $31.82 \pm 6.30$ & $34.88 \pm 7.68$ & 0.003 \\
\hline Neck girth $(\mathrm{cm})$ & $39.64 \pm 6.19$ & $39.17 \pm 5.50$ & 0.61 \\
\hline ESS & $14.64 \pm 3.88$ & $14.13 \pm 3.99$ & 0.39 \\
\hline STOP-BANG & $5.61 \pm 1.62$ & $4.76 \pm 1.75$ & 0.0009 \\
\hline $\mathrm{AHI}$ & $49.89 \pm 24.70$ & $44.57 \pm 23.96$ & 0.15 \\
\hline STOP-BANG & $\mathrm{n}(\%)$ & $\mathrm{n}(\%)$ & $p$ value \\
\hline Snoring & $123(90)$ & $56(89)$ & 0.85 \\
\hline Tiredness & $122(89)$ & $57(90)$ & 0.76 \\
\hline Observed choking & $101(73)$ & $43(68)$ & 0.42 \\
\hline Pressure & $95(69)$ & $41(65)$ & 0.55 \\
\hline $\mathrm{BMI}>35 \mathrm{~kg} / \mathrm{m}^{2}$ & $39(29)$ & $29(46)$ & 0.015 \\
\hline Age $>50$ years & $70(51)$ & $42(67)$ & 0.04 \\
\hline Neck girth $>40 \mathrm{~cm}$ & $85(62)$ & $38(60)$ & 0.82 \\
\hline Gender & $137(100)$ & $0(0)$ & $N A$ \\
\hline STOP-BANG Score & $\mathrm{n}(\%)$ & $\mathrm{n}(\%)$ & $p$ value \\
\hline $0-2$ & $7(5)$ & $8(13)$ & 0.06 \\
\hline $3-4$ & $23(17)$ & $17(27)$ & 0.09 \\
\hline$\geq 5$ & $107(78)$ & $38(60)$ & 0.0088 \\
\hline Obesity & $\mathrm{n}(\%)$ & $\mathrm{n}(\%)$ & $p$ value \\
\hline Obese (BMI $\geq 30$ ) & $88(64)$ & $49(78)$ & 0.055 \\
\hline Morbid obese $(\mathrm{BMI} \geq 40)$ & $15(11)$ & $17(27)$ & 0.004 \\
\hline Severity of OSA & $\mathrm{n}(\%)$ & $\mathrm{n}(\%)$ & $p$ value \\
\hline Normal & $1(1)$ & $1(2)$ & 0.57 \\
\hline Mild & $11(8)$ & $5(8)$ & 0.98 \\
\hline Moderate & $21(15)$ & $15(24)$ & 0.15 \\
\hline Severe & 104 (76) & $42(66)$ & 0.17 \\
\hline
\end{tabular}

Bold digits interpreted as significance difference or correlation between two groups or variables

Table 3: Comparison between obese and morbid obese group

\begin{tabular}{lccc}
\hline & Obese $(\mathrm{n}=137)$ & Morbid obese $(\mathrm{n}=32)$ & \\
\cline { 2 - 3 } & $\left(\mathrm{BMI} \geq 30 \mathrm{~kg} / \mathrm{m}^{2}\right)$ & $\left(\mathrm{BMI} \geq 40 \mathrm{~kg} / \mathrm{m}^{2}\right)$ & p value \\
\hline Age (years) & $52.71 \pm 11.78$ & $55.47 \pm 10.79$ & 0.28 \\
Weight $(\mathrm{kg})$ & $95.07 \pm 11.60$ & $109.74 \pm 16.28$ & $<0.0001$ \\
Height $(\mathrm{cm})$ & $162.29 \pm 8.21$ & $157.56 \pm 9.99$ & 0.0055 \\
BMI $\left(\mathrm{kg} / \mathrm{m}^{2}\right)$ & $36.14 \pm 5.20$ & $43.97 \pm 3.75$ & $<0.0001$ \\
Neck girth $(\mathrm{cm})$ & $40.74 \pm 5.17$ & $42.03 \pm 4.71$ & 0.2 \\
ESS & $15.20 \pm 3.68$ & $14.78 \pm 3.64$ & 0.56 \\
STOP-BANG & $5.70 \pm 1.60$ & $6.16 \pm 1.76$ & 0.16 \\
AHI & $51.81 \pm 24.93$ & $46.53 \pm 26.20$ & 0.28 \\
\hline
\end{tabular}

(Contd...) 
Table 3: (Contd...)

\begin{tabular}{lccc}
\hline & Obese $(\mathrm{n}=137)$ & Morbid obese $(\mathrm{n}=32)$ & \\
\cline { 2 - 3 } & $\left(\mathrm{BMI} \geq 30 \mathrm{~kg} / \mathrm{m}^{2}\right)$ & $\left(\mathrm{BMI} \geq 40 \mathrm{~kg} / \mathrm{m}^{2}\right)$ & p value \\
\hline STOP-BANG & $\mathrm{n}(\%)$ & $\mathrm{n}(\%)$ & p value \\
\hline Snoring & $128(93)$ & $29(90)$ & 0.56 \\
Tiredness & $127(92)$ & $29(90)$ & 0.69 \\
Observed choking & $102(74)$ & $25(78)$ & 0.67 \\
Pressure & $101(73)$ & $24(75)$ & 0.88 \\
BMI $>35 \mathrm{~kg} / \mathrm{m}^{2}$ & $68(49)$ & $32(100)$ & $\mathrm{NA}$ \\
Age $>50$ years & $81(59)$ & $23(71)$ & 0.18 \\
Neck girth $>40 \mathrm{~cm}$ & $95(69)$ & $26(81)$ & 0.18 \\
Gender & $88(64)$ & $15(47)$ & 0.07 \\
\hline STOP-BANG Score & $\mathrm{n}(\%)$ & $\mathrm{n}(\%)$ & $\mathrm{p} \mathrm{value}$ \\
\hline 0-2 & $6(4)$ & $1(3)$ & 0.75 \\
3-4 & $23(17)$ & $4(12)$ & 0.55 \\
$\geq 5$ & $108(79)$ & $27(85)$ & 0.48 \\
\hline Severity of OSA & $\mathrm{n}(\%)$ & $\mathrm{n}(\%)$ & $\mathrm{p}$ value \\
\hline Normal & $2(2)$ & $2(6)$ & 0.11 \\
Mild & $6(4)$ & $2(6)$ & 0.65 \\
Moderate & $26(19)$ & $6(19)$ & 0.98 \\
Severe & $103(75)$ & $22(69)$ & 0.56 \\
\hline Bold dits & & &
\end{tabular}

Bold digits interpreted as significance difference or correlation between two groups or variables

Table 4: STOP-BANG Score profile

\begin{tabular}{|c|c|c|c|c|}
\hline & \multicolumn{3}{|c|}{ STOP-BANG Score } & \\
\hline & $0-2(n=15)$ & $3-4(n=40)$ & $\geq 5(n=145)$ & \\
\hline Age (years) & $39.53 \pm 15.78$ & $46.9 \pm 15.92$ & $54.44 \pm 11.22$ & \\
\hline Weight (kg) & $69.87 \pm 27.74$ & $79.38 \pm 19.22$ & $89.77 \pm 17.90$ & \\
\hline Height (cm) & $157.67 \pm 14.17$ & $161.4 \pm 10.69$ & $162.47 \pm 9.58$ & \\
\hline BMI $\left(\mathrm{kg} / \mathrm{m}^{2}\right)$ & $27.26 \pm 8.56$ & $30.54 \pm 7.10$ & $33.97 \pm 6.25$ & \\
\hline Neck girth (cm) & $31.6 \pm 6.75$ & $35.28 \pm 5.57$ & $41.48 \pm 4.59$ & \\
\hline ESS & $9.80 \pm 3.95$ & $11.63 \pm 3.00$ & $15.74 \pm 3.32$ & \\
\hline STOP-BANG & $1.80 \pm 0.41$ & $3.55 \pm 0.50$ & $6.20 \pm 0.98$ & \\
\hline $\mathrm{AHI}$ & $22.87 \pm 24.91$ & $30.53 \pm 18.22$ & $55.72 \pm 21.70$ & \\
\hline STOP-BANG & $\mathrm{n}(\%)$ & $\mathrm{n}(\%)$ & $\mathrm{n}(\%)$ & $p$ value \\
\hline Snoring & $3(20)$ & $32(80)$ & $144(99)$ & $<0.0001$ \\
\hline Tiredness & $9(60)$ & $27(67)$ & $143(98)$ & $<0.0001$ \\
\hline Observed choking & $4(27)$ & $17(42)$ & $123(85)$ & $<0.0001$ \\
\hline Pressure & $3(20)$ & $10(25)$ & $123(85)$ & $<0.0001$ \\
\hline $\mathrm{BMI}>35 \mathrm{~kg} / \mathrm{m}^{2}$ & $2(13)$ & $8(20)$ & $58(40)$ & 0.013 \\
\hline Age $>50$ years & $4(27)$ & $15(37)$ & $93(64)$ & $<0.0001$ \\
\hline Neck girth $>40 \mathrm{~cm}$ & $2(13)$ & $10(25)$ & $111(77)$ & $<0.0001$ \\
\hline Gender & $7(47)$ & $23(57)$ & $107(74)$ & 0.024 \\
\hline Obesity & $\mathrm{n}(\%)$ & n (\%) & $\mathrm{n}(\%)$ & $\mathrm{p}$ value \\
\hline Obese $\left(\mathrm{BMI} \geq 30 \mathrm{~kg} / \mathrm{m}^{2}\right)$ & $6(40)$ & $23(57)$ & $108(74)$ & 0.009 \\
\hline Morbid obese $\left(\mathrm{BMI} \geq 40 \mathrm{~kg} / \mathrm{m}^{2}\right)$ & $1(7)$ & $4(10)$ & $27(17)$ & 0.25 \\
\hline Severity of OSA & $\mathrm{n}(\%)$ & $\mathrm{n}(\%)$ & $\mathrm{n}(\%)$ & $\mathrm{p}$ value \\
\hline Normal & $0(0)$ & $1(2.5)$ & $1(0.7)$ & NA \\
\hline Mild & $8(53)$ & $5(12)$ & $3(2)$ & $<0.0001$ \\
\hline Moderate & $4(27)$ & $18(45)$ & $14(10)$ & $<0.0001$ \\
\hline Severe & $3(20)$ & $16(40)$ & $127(88)$ & $<0.0001$ \\
\hline
\end{tabular}

Bold digits interpreted as significance difference or correlation between two groups or variables 


\section{Discussion}

Snoring is the most common symptom in our study. Snoring is present in all spectrum of excessive daytime sleepiness (EDS) - in ascending order of severity-including primary snoring, upper airway resistance syndrome (UARS), OSA, central sleep apnea, complex sleep apnea, and obesity hypoventilation syndrome. $\mathrm{BMI}>30 \mathrm{~kg} / \mathrm{m}^{2}$ with neck girth $>40 \mathrm{~cm}$ is associated with high ESS and severity of sleep apnea. There is a positive correlation between variables like neck girth, ESS, and STOP-BANG Score with AHI as is depicted in Figure 1 (Tables 5 and 6).

A study to predict associated sleep apnea activity with high sensitivity and an $\mathrm{AHI}$ of 15 or higher confirmed four terms observed by bed partners: apnea, hypertension, $\mathrm{BMI}$, and age. ${ }^{35}$

The advantage of the ESS is that it shows an average sleep tendency. The average ESS score of 30 normal men and women mean + SD was $5.9+2.2 .^{36}$

Snoring is very common. In the United Kingdom, a telephonic survey found out that $40 \%$ of the full populace who've loud breathing with an elevated incidence in men. ${ }^{37}$ The snoring is one of the most common symptoms of OSA and occurs in up to $70-95 \%$ of patients with the syndrome. ${ }^{38}$ On the contrary, the likelihood of OSA is much lower due to the absence of snoring, with only $3-6 \%$ reporting if not habitually snores.
Considering the severity of symptoms, the probability of indicating apnea activity gradually increased. For example, light snoring had an odds ratio of 2.1 and very severe snoring was 21.1 compared to those without snoring. Additionally, data on BMI and gender showed a $10 \%$ improvement in predictive power. ${ }^{36}$

Patients experiencing tiredness, malaise, or fatigue may feel lethargic, but not necessarily hypersomnia. Conditions such as anemia, congestive heart failure (CHF), depression, and hypothyroidism can accompany fatigue. Distinguishing between drowsiness and fatigue can eventually lead to a different diagnosis. However, sufferers with OSA use phrases consisting of fatigue, tiredness, or loss of power to explain their personal signs and symptoms of sleepiness.

Some patients report that they stopped breathing or became awake during sleep or that the patient was choking or feeling severe panic in the middle of the night. However, the combination of these symptoms, such as snoring and observed choking/apnea, better predicts OSA. ${ }^{39}$

To date, hypertension (pressure) is the most well-documented and well-studied result of OSA. The greater the severity of OSA as measured by the Respiratory Disorder Index (RDI), the greater the risk of systemic hypertension. ${ }^{40}$ A 4-year follow-up study in the Wisconsin Sleep Cohort shows a dose-response relationship

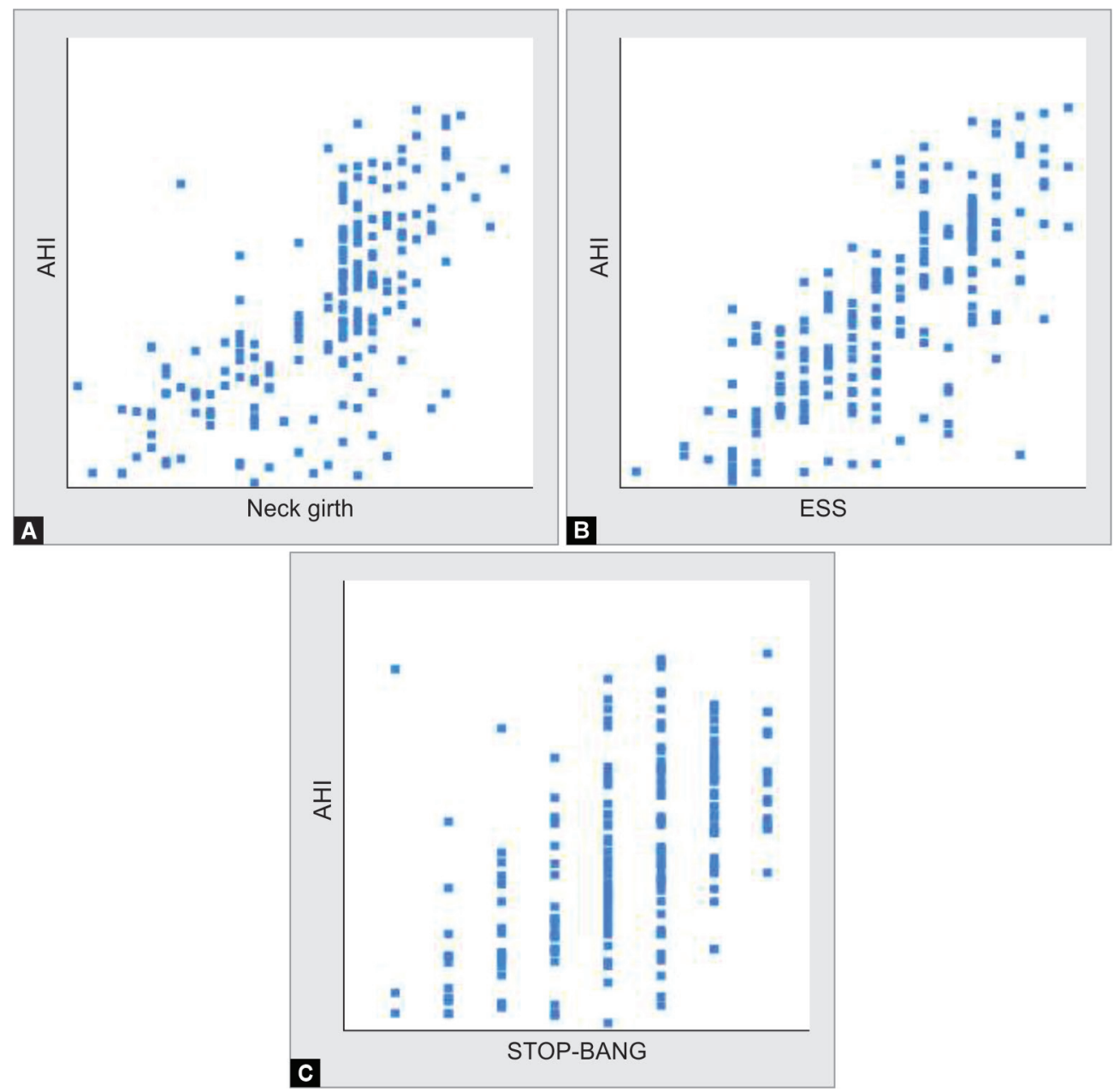

Figs 1 A to C: Pearson correlation counted between neck girth $(r=0.68)$, ESS $(r=0.73)$, and STOP-BANG Score $(r=0.55)$ with AHI with a significant $p$ value $(<0.0001)$ in $(A)$ to $(C)$, respectively 
Table 5: Epworth sleepiness scale score profile

\begin{tabular}{|c|c|c|c|c|c|}
\hline ESS & $\begin{array}{c}\text { Normal group } \\
\text { ESS }(\leq 10)\end{array}$ & $\begin{array}{l}\text { Mild (11-14) } \\
\quad(\mathrm{n}=61)\end{array}$ & $\begin{array}{c}\text { Moderate (15-17) } \\
\quad(n=45)\end{array}$ & $\begin{array}{c}\text { Severe }(18-24) \\
\quad(n=56)\end{array}$ & \\
\hline Age (years) & $49.84 \pm 16.82$ & $52.1 \pm 11.90$ & $51.4 \pm 15.11$ & $53.18 \pm 10.85$ & \\
\hline Weight (kg) & $78 \pm 22.35$ & $82.33 \pm 18.18$ & $90.56 \pm 21.97$ & $92.46 \pm 15.36$ & \\
\hline Height $(\mathrm{cm})$ & $161.5 \pm 10.55$ & $160.8 \pm 10.72$ & $161.6 \pm 11.38$ & $163.59 \pm 8.37$ & \\
\hline BMI $\left(\mathrm{kg} / \mathrm{m}^{2}\right)$ & $29.88 \pm 8.30$ & $31.73 \pm 6.14$ & $34.40 \pm 7.21$ & $34.60 \pm 5.53$ & \\
\hline Neck girth $(\mathrm{cm})$ & $33.03 \pm 5.17$ & $37.56 \pm 5.43$ & $42.62 \pm 3.71$ & $43.48 \pm 3.25$ & \\
\hline ESS & $8.68 \pm 1.38$ & $12.69 \pm 1.18$ & $16.02 \pm 0.75$ & $19.11 \pm 1.26$ & \\
\hline STOP-BANG & $3.61 \pm 1.53$ & $5.05 \pm 1.47$ & $6.04 \pm 1.31$ & $6.27 \pm 1.30$ & \\
\hline $\mathrm{AHI}$ & $22.84 \pm 13.48$ & $36.93 \pm 15.82$ & $57.91 \pm 20.39$ & $69.93 \pm 17.52$ & \\
\hline STOP-BANG & n (\%) & n (\%) & n (\%) & n (\%) & $\mathrm{p}$ value \\
\hline Snoring & $23(61)$ & $56(92)$ & $44(98)$ & $56(100)$ & NA \\
\hline Tiredness & $29(76)$ & $52(85)$ & $44(98)$ & $54(96)$ & $<0.0001$ \\
\hline Observed choking & $11(29)$ & $41(67)$ & $40(89)$ & $52(93)$ & $<0.0001$ \\
\hline Pressure & $15(39)$ & $40(66)$ & $36(80)$ & $45(80)$ & 0.0013 \\
\hline $\mathrm{BMI}>35 \mathrm{~kg} / \mathrm{m}^{2}$ & $9(24)$ & $15(25)$ & $16(36)$ & $28(50)$ & 0.57 \\
\hline Age $>50$ years & $19(50)$ & $38(62)$ & $23(51)$ & $32(57)$ & $<0.0001$ \\
\hline Neck girth $>40 \mathrm{~cm}$ & $6(16)$ & $36(59)$ & $39(87)$ & $52(93)$ & $<0.0001$ \\
\hline Gender & $24(63)$ & $41(67)$ & $33(73)$ & $39(70)$ & 0.78 \\
\hline STOP-BANG Score & n (\%) & $\mathrm{n}(\%)$ & n (\%) & n (\%) & $\mathrm{p}$ value \\
\hline $0-2$ & $9(24)$ & $4(7)$ & $1(2)$ & $1(2)$ & $<0.0001$ \\
\hline $3-4$ & $18(47)$ & $16(26)$ & $3(7)$ & $3(5)$ & $<0.0001$ \\
\hline$\geq 5$ & $11(29)$ & $41(67)$ & $41(91)$ & $52(93)$ & $<0.0001$ \\
\hline Obesity & n (\%) & n (\%) & n (\%) & n (\%) & $p$ value \\
\hline Obese (BMI $\geq 30 \mathrm{~kg} / \mathrm{m}^{2}$ ) & $21(55)$ & $35(57)$ & $35(33)$ & $46(82)$ & 0.0042 \\
\hline Morbid obese $\left(\mathrm{BMI} \geq 40 \mathrm{~kg} / \mathrm{m}^{2}\right)$ & $6(16)$ & $7(2)$ & $10(22)$ & $9(20)$ & 0.53 \\
\hline Severity of OSA & $\mathrm{n}(\%)$ & $\mathrm{n}(\%)$ & $\mathrm{n}(\%)$ & $\mathrm{n}(\%)$ & $\mathrm{p}$ value \\
\hline Normal & $2(5)$ & $0(0)$ & $0(0)$ & $0(0)$ & NA \\
\hline Mild & $10(26)$ & $4(7)$ & $1(2)$ & $1(2)$ & $<0.0001$ \\
\hline Moderate & $14(37)$ & $16(26)$ & $5(11)$ & $1(2)$ & $<0.0001$ \\
\hline Severe & $12(32)$ & $41(67)$ & $39(87)$ & $54(96)$ & $<0.0001$ \\
\hline
\end{tabular}

Bold digits interpreted as significance difference or correlation between two groups or variables

Table 6: Severity of sleep apnea details

\begin{tabular}{lccc}
\hline AHl severity & Mild $(\mathrm{n}=16)$ & Moderate $(\mathrm{n}=36)$ & Severe $(\mathrm{n}=146)$ \\
\hline Age (years) & $46.5 \pm 14.83$ & $51.22 \pm 15.38$ & $52.49 \pm 12.75$ \\
Weight $(\mathrm{kg})$ & $75.00 \pm 26.41$ & $86.25 \pm 20.25$ & $87.01 \pm 18.53$ \\
Height $(\mathrm{cm})$ & $161.56 \pm 15.29$ & $161.33 \pm 11.26$ & $162.14 \pm 9.37$ \\
BMI $\left(\mathrm{kg} / \mathrm{m}^{2}\right)$ & $28.34 \pm 8.47$ & $33.02 \pm 6.66$ & $33.02 \pm 6.49$ \\
Neck girth $(\mathrm{cm})$ & $32.81 \pm 6.25$ & $34.00 \pm 5.76$ & $41.06 \pm 4.45$ \\
ESS & $9.88 \pm 4.10$ & $11.61 \pm 2.72$ & $15.77 \pm 3.29$ \\
STOP-BANG & $3.00 \pm 1.59$ & $4.19 \pm 1.43$ & $5.89 \pm 1.40$ \\
AHI & $8.19 \pm 2.69$ & $22.69 \pm 3.89$ & $59.50 \pm 18.11$ \\
\hline
\end{tabular}


Predictive Performance of Suspected Sleep Apnea Individuals

\begin{tabular}{lcccc}
\hline STOP-BANG & $\mathrm{n}(\%)$ & $\mathrm{n}(\%)$ & $\mathrm{n}(\%)$ & $\mathrm{p}$ value \\
\hline Snoring & $6(38)$ & $31(86)$ & $141(97)$ & $<0.0001$ \\
Tiredness & $8(50)$ & $28(78)$ & $142(97)$ & $<0.0001$ \\
Observed choking & $8(50)$ & $17(47)$ & $119(82)$ & 0.0002 \\
Pressure & $4(25)$ & $15(42)$ & $116(79)$ & $<0.0001$ \\
BMI $>35 \mathrm{~kg} / \mathrm{m}^{2}$ & $3(19)$ & $11(31)$ & $52(36)$ & 0.37 \\
Age $>50$ years & $7(44)$ & $20(56)$ & $83(57)$ & 0.61 \\
Neck girth $>40 \mathrm{~cm}$ & $2(13)$ & $6(20)$ & $114(78)$ & $<0.0001$ \\
Gender & $11(69)$ & $21(58)$ & $104(71)$ & 0.33 \\
\hline
\end{tabular}

Bold digits interpreted as significance difference or correlation between two groups or variables

between $\mathrm{AHI}$ and hypertension. A risk ratio of 4.54 for hypertension was associated with more than $15 \mathrm{AHI}$ events per hour. ${ }^{41}$ Patients with refractory hypertension (requires at least three pressures) may be particularly at risk for OSA. ${ }^{42}$

There is a clear correlation between OSA and overweight. A Wisconsin Sleep Cohort shows that patients with mild OSA have a sixfold risk of developing moderate or severe OSA when they gain only $10 \%$ of their body weight. Among the cohort of morbid obese $\left(\mathrm{BMI}>40 \mathrm{~kg} / \mathrm{m}^{2}\right), 70 \%$ of individuals suffer from OSA.

There are several large cohort studies that have been shown to increase the prevalence of sleep apnea among men and women aged 60 years and older by two to three times that of the middleaged population..$^{43-48}$

The study shows that the neck circumference is a strong predictor of $\mathrm{OSA}^{49}$ as there is an increase in excess fat in the anterior and lateral regions of the upper airways in both obese and non-obese patients. ${ }^{50}$ If the neck circumference is larger than $48 \mathrm{~cm}$, the risk of OSA is high, and if the circumference is less than $37 \mathrm{~cm}$, the risk of OSA is low.

Male gender is an important risk factor. ${ }^{22}$ In a Wisconsin Sleep Cohort study, postmenopausal women were more than three times more likely to have a moderate-to-severe OSA than premenopausal women with age-matched BMI. ${ }^{51}$

\section{ConcLusion}

In outpatients, STOP-BANG Score and ESS are simple and easy measures for suspicion and diagnosis of OSA. STOP-BANG Score $\geq 3$ and ESS $>10$ increase the probability of OSA.

\section{References}

1. World Health Organization. Obesity and overweight. World Health Organization; 2017. Available from: http://wwwwhoint/news -room/ fact-sheets/detail/obesity and overweight [Accessed on June 24, 2018].

2. Available from: https://www.worldobesity.org/about/about-obesity/ prevalence-of-obesity.

3. NCD Risk Factor Collaboration (NCD-RisC). Trends in adult bodymass index in 200 countries from 1975 to 2014: a pooled analysis of 1698 population-based measurement studies with 19.2 million participants. Lancet 2016;387(10026):1377-1396. DOI: 10.1016/S01406736(16)30054-X.

4. Available from: https://ourworldindata.org/obesity.

5. Available from: https://data.worldobesity.org/tables/prevalence-ofadult-overweight-obesity-2/.

6. Lugaresi E, Cirignotta F, Coccagna G, et al. Some epidemiological data on snoring and cardiocirculatory disturbances. Sleep 1980;3(3): 221-224. DOI: 10.1093/sleep/3.3-4.221.
7. Young T, Palta M, Dempsey J, et al. The occurrence of sleepdisordered breathing among middle-aged adults. N Engl J Med 1993:328(17):1230-1235. DOI: 10.1056/NEJM199304293281704.

8. Pevernagie D, Aarts RM, De Meyer M. The acoustics of snoring. Sleep Med Rev 2010;14(2):131-144. DOI: 10.1016/j.smrv.2009.06.002.

9. Wilson K, Stoohs RA, Mulrooney TF, et al. The snoring spectrum: acoustic assessment of snoring sound intensity in 1,139 individuals undergoing polysomnography. Chest 1999;115(3):762-770. DOI: $10.1378 /$ chest.115.3.762.

10. Guilleminault C, Stoohs R, Duncan S. Snoring (I). Daytime sleepiness in regular heavy snorers. Chest 1991;99(1):40-48. DOI: 10.1378/ chest.99.1.40.

11. Dalmasso F, Prota R. Snoring: analysis, measurement, clinical implications and applications. Eur Respir J 1996;9(1):146-159. DOI: 10.1183/09031936.96.09010146.

12. Thorpy MJ. Classification of sleep disorders. Neurotherapeutics 2012;9(4):687-701. DOI: 10.1007/s13311-012-0145-6.

13. Shin C, Kim J, Kim J, et al. Association of habitual snoring with glucose and insulin metabolism in nonobese Korean adult men. Am J Respir Crit Care Med 2005;171(3):287-291. DOI: 10.1164/rccm.2004079060C.

14. Marchesini G, Pontiroli A, Salvioli G, et al. Snoring, hypertension and Type 2 diabetes in obesity. Protection by physical activity. J Endocrinol Invest 2004;27(2):150-157. DOI: 10.1007/BF03346260.

15. Oliven A, Aspandiarov E, Gankin I, et al. Collapsibility of the relaxed pharynx and risk of sleep apnoea. Eur Respir J 2008;32:1309-1315. DOI: 10.1183/09031936.00139407.

16. Peppard PE, Young T, Palta M, et al. Longitudinal study of moderate weight change and sleep-disordered breathing. JAMA 2000;284(23):3015-3021. DOI: 10.1001/jama.284.23.3015.

17. Siegfried W, Siegfried A, Rabenbauer M, et al. Snoring and sleep apnea in obese adolescents: Effect of long-term weight loss-rehabilitation. Sleep Breath 1999;3:83-88. DOI: 10.1007/s11325-999-0083-7.

18. Shukla AD, Jain S, Mishra R, et al. Does 'weight reduction' help all adult snorers? Lung India 2013;30(1):16-19. DOI: 10.4103/0970-2113.106123.

19. Wickramasinghe $\mathrm{H}$, Rowley J. Medscape - ACCP AASM.

20. Silverberg DS, Oksenberg A. Are sleep related breathing disorder important contributing factors to the production of essential hypertension? Curr Hypertens Rep 2001;3(3):209-215. DOI: 10.1007/ s11906-001-0040-8.

21. Worsnop CJ, Naughton MT, Barter CE, et al. The prevalence of obstructive sleep apnea in hypertensives. Am J Respir Crit Care Med 1998;157(1):111-115. DOI: 10.1164/ajrccm.157.1.9609063.

22. Block AJ, Boysen PG, Wynne JW, et al. Sleep apnea, hypopnea and oxygen desaturation in normal subjects: A strong male predominance. N Engl J Med 1979;300(10):513-517. DOI: 10.1056/ NEJM197903083001001.

23. Gislason T, Benediktsdottir B, Bjornsson JK, et al. Snoring, hypertension, and the sleep apnea syndrome. An epidemiologic survey of middle-aged women. Chest 1993;103(4):1147-1151. DOI: 10.1378/chest.103.4.1147. 
24. Guilleminault C, Stoohs R, Kim YD, et al. Upper airway sleepdisordered breathing in women. Ann Intern Med 1995;122(7):493-501. DOI: 10.7326/0003-4819-122-7-199504010-00003.

25. Young T, Hutton R, Finn L, et al. The gender bias in sleep apnea diagnosis. Are women missed because they have different symptoms? Arch Intern Med 1996;156(21):2445-2451. DOI: 10.1001.

26. Redline S, Kump K, Tishler PV, et al. Gender differences in sleep disordered breathing in a community-based sample. Am J Respir Crit Care Med 1994;149(3 Pt 1):722-726. DOI: 10.1164/ajrccm.149.3.8118642.

27. Popovic RM, White DP. Influence of gender on waking genioglossal electromyogram and upper airway resistance. Am J Respir Crit Care Med 1995;152(2):725-731. DOI: 10.1164/ajrccm.152.2.7633734.

28. Popovic RM, White DP. Upper airway muscle activity in normal women: influence of hormonal status. J Appl Physiol 1998;84(3):10551062. DOI: 10.1152/jappl.1998.84.3.1055.

29. Brooks LJ, Strohl KP. Size and mechanical properties of the pharynx in healthy men and women. Am Rev Respir Dis 1992;146(6):1394-1397. DOI: 10.1164/ajrccm/146.6.1394.

30. Brown IG, Zamel N, Hoffstein V. Pharyngeal cross-sectional area in normal men and women. J Appl Physiol 1986;61(3):890-895. DOI: 10.1152/jappl.1986.61.3.890.

31. Kapur VK, Auckley DH, Chowdhuri S, et al. Clinical practice guideline for diagnostic testing for adult obstructive sleep apnea: an American Academy of Sleep Medicine Clinical Practice Guideline. J Clin Sleep Med 2017;13(3):479-504. DOI: 10.5664/jcsm.6506.

32. Sateia MJ. International classification of sleep disorders-third edition: highlights and modifications. Chest 2014;146(5):1387-1394. DOI: 10.1378/chest.14-0970.

33. Park JG, Ramar K, Olson EJ. Updates on definition, consequences, and management of obstructive sleep apnea. Mayo Clin Proc 2011;86(6):549-554. DOI: 10.4065/mcp.2010.0810.

34. www.healthline.com.

35. Crocker B, Olson LG, Saunders NA, et al. Estimation of the probability of disturbed breathing during sleep before a sleep study. Am J Respir Crit Care Med 1990;142(1):14-18. DOI: 10.1164/ajrccm/142.1.14.

36. Randerath WJ. Sleep apnoea - current diagnosis and treatment. In: Ruhle KH. History and questionnaire. Karger Medical and Scientific Publisher. 2006. p. 38.

37. Ohayon MM, Guillemiault C, Priest RG, et al. Snoring and breathing pauses during sleep: telephone interview survey of a United Kingdom population sample. BMJ 1997;314(7084):860-863. DOI: 10.1136/ bmj.314.7084.860.

38. Whyte KF, Allen MB, Jeffrey $A A$, et al. Clinical features of the sleep apnea/ hypopnea syndrome. Q J Med 1989;72(267):659-666. DOI: 10.1056.
39. Randerath WJ. Sleep apnoea - current diagnosis and treatment. In: Yim S. OSA - clinical presentation, diagnosis and treatment. Karger Medical and Scientific Publisher. 2006. p. 121.

40. Lavie $P$, Herer $P$, Hoffstein V. Obstructive sleep apnoea syndrome as a risk factor for hypertension: population study. BMJ 2000;320(7233): 479-482. DOI: $10.1136 / \mathrm{bmj} .320 .7233 .479$

41. Peppard PE, Young T, Palta M, et al. Prospective study of the association between sleep-disordered breathing and hypertension. N Engl J Med 2000;342(19):1378-1384. DOI: 10.1056/ NEJM200005113421901.

42. Randerath WJ. Sleep apnoea - current diagnosis and treatment. In Yim S. OSA - clinical presentation, diagnosis and treatment. Karger Medical and Scientific Publisher. 2006. p. 131.

43. Bixler E, Vgontazas A, Ten Have T, et al. Effects of age on sleep apnea in men. Am J Respir Crit Care Med 1998;157(1):144-148. DOI: 10.1164/ ajrccm.157.1.9706079.

44. Bixler E, Vgontzas $\mathrm{A}$, Lin $\mathrm{H}$, et al. Prevalence of sleep-disordered breathing in women. Am J Respir Crit Care Med 2001;163(3 Pt 1):608-613. DOI: 10.1164/ajrccm.163.3.9911064.

45. Durán J, Esnaola S, Rubio R, et al. Obstructive sleep apnea-hypopnea and related clinical features in a population-based sample of subjects aged 30-70 yr. Am J Respir Crit Care Med 2001;163(3 Pt 1):685-689. DOI: 10.1164/ajrccm.163.3.2005065.

46. Redline S. Epidemiology of sleep-disordered breathing. Semin Respir Crit Care Med 1998;19(2):113-122. DOI: 10.1055/s-2007-1009388.

47. Young T, Shahar E, Nieto FJ, et al. Predictors of sleep-disordered breathing in community dwelling adults: the Seep Heart Health Study. Arch Intern Med 2002;162(8):893-900. DOI: 10.1001/ archinte.162.8.893.

48. Ancoli-Israel S, Kripke D, Klauber M, et al. Sleep-disordered breathing in community-dwelling elderly. Sleep 1991;14(6):486-495. DOI: 10.1093/sleep/14.6.486.

49. Stradling JR, Crosby JH. Predictors and prevalence of obstructive sleep apnea and snoring in 1001 middle aged men. Thorax 1991;46(2):85-90. DOI: 10.1136/thx.46.2.85.

50. Mortimore IL, Marshall I, Wraith PK, et al. Neck and total body fat deposition in nonobese and obese patients with sleep apnea compared with that in control subjects. Am J Respir Crit Care Med 1998;157(1):280-283. DOI: 10.1164/ajrccm.157.1.9703018.

51. Young T, Finn L, Austin D, et al. Menopausal status and sleepdisordered breathing in the Wisconsin Sleep Cohort study. Am J Respir Crit Care Med 2002;167(9):1181-1185. DOI: 10.1164/ rccm.200209-1055OC. 